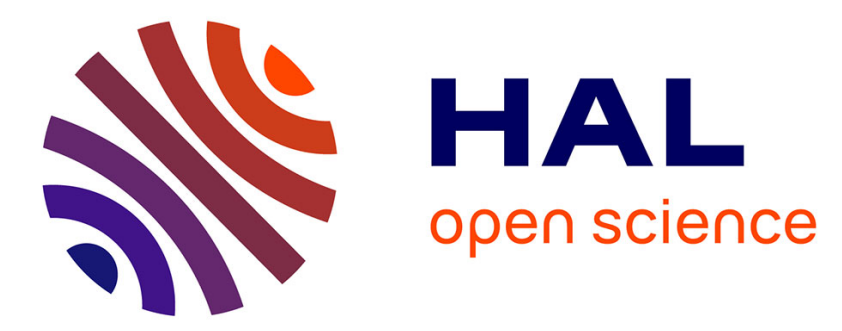

\title{
Critical coupling and extreme confinement in nanogap antennas
}

\author{
Ludivine Emeric, Claire Deeb, Fabrice Pardo, Jean-Luc Pelouard
}

\section{To cite this version:}

Ludivine Emeric, Claire Deeb, Fabrice Pardo, Jean-Luc Pelouard. Critical coupling and extreme confinement in nanogap antennas. Optics Letters, 2019, 44 (19), pp.4761-4764. 10.1364/OL.44.004761. hal-02319979

\section{HAL Id: hal-02319979 \\ https://hal.science/hal-02319979}

Submitted on 18 Oct 2019

HAL is a multi-disciplinary open access archive for the deposit and dissemination of scientific research documents, whether they are published or not. The documents may come from teaching and research institutions in France or abroad, or from public or private research centers.
L'archive ouverte pluridisciplinaire HAL, est destinée au dépôt et à la diffusion de documents scientifiques de niveau recherche, publiés ou non, émanant des établissements d'enseignement et de recherche français ou étrangers, des laboratoires publics ou privés. 


\title{
Critical coupling and extreme confinement in nanogap antennas
}

\author{
Ludivine Emeric $^{1,2}$, Claire Deeb ${ }^{1, \ddagger}$, Fabrice Pardo $^{1}$, and Jean-Luc Pelouard ${ }^{1}{ }^{*}$ \\ ${ }^{1}$ Centre for Nanoscience and Nanotechnology (C2N), CNRS, Université Paris-Saclay, 10 Boulevard Thomas Gobert, 91120 Palaiseau, France \\ ${ }^{2}$ ONERA - The French Aerospace Lab, Chemin de la Hunière, Université Paris-Saclay, 91761 Palaiseau, France \\ $\ddagger$ Present address: Almae Technologies, Route de Nozay, 91460 Marcoussis, France \\ *Corresponding author: jean-luc.pelouard@c2n.upsaclay.fr
}

Compiled September 4, 2019

\begin{abstract}
Nanogap antennas are compelling structures for squeezing light into ultrasmall volumes. However, when gaps are shrunk down to the nanometer scale, mode losses dramatically increase. In this Letter, we report conditions of critical coupling, between arrays of nanogap resonant metal-insulator-metal (MIM) antennas and free-space. Adapting the antennas density, critical coupling is achievable for any thickness of insulator, from $100 \mathrm{~nm}$ down to $0.1 \mathrm{~nm}$. The fundamental optical mode can be described as continuous transitions through three types of modes: perfect MIM mode, coupling between MIM mode and surface plasmon polariton (SPP), and gap plasmon mode. We found that the space between adjacent antennas is an essential parameter to perform critical coupling for thinner gaps. These results pave the way towards understanding extreme confinement in nanogap antennas structures such as MIM or nanoparticle arrays.
\end{abstract}

Metallic nanoantennas have been widely used to confine electromagnetic field at the subwavelength scale [1-4]. Their ability to support strongly localized surface plasmons make them excellent systems to design perfect absorbers.

The emergence of reliable fabrication techniques to produce well-controlled gaps have prompted the development of narrow gap antennas for achieving even higher field confinement and enhancing non-linear effects such as optical rectification for photodetection [5], biosensing [6], nonlinear harmonic generation $[7,8]$, surface enhanced spectroscopy [9], and enhanced spontaneous emission [10]. Tunneling junction-assisted-antennas were also shown to support light emission [11-13]. With this variety of application areas, it is necessary to have a strong knowledge of the optical properties of nanogap antennas, particularly when their size is scaled down to deep subwavelength dimensions.

Under critical coupling, the incident energy is totally absorbed within the antennas. Critical coupling is characterized by a perfect match between the non-radiative and radiative damping rates, according to the temporal coupled mode theory $[14,15]$.
At a fixed wavelength and in order to maintain critical coupling, decreasing the insulator thickness implies decreasing the width of the antennas, thus changing both radiative and nonradiative damping rates. Under-coupling and over-coupling cause non-perfect absorption, due to two opposite behaviors (Fig. 1(a)). An under-coupled system is characterized by a narrower resonance than that at critical coupling: the system is restrained by the limited amount of incident energy that can enter the resonator. Whereas an over-coupled structure has a broader resonance: the system is saturated and cannot absorb all the incoming light. The optical properties of antennas are therefore highly dependent on their dimensions [15]. Shrinking the gap size results in a higher confinement, but also a large part of the field penetrates into the metal, leading to higher losses. As a result, balance between radiative and non-radiative processes has to be reconsidered for each gap thickness. Moreover, conditions for achieving critical coupling in sub-nanometer gap antennas remain unknown.

In this Letter, we propose to study critical coupling of the fundamental mode in MIM nanoantennas as a function of the gap size. The studied antennas consist of a semi-infinite gold film, a continuous $\mathrm{SiO}_{2}$ layer of thickness $h_{\text {gap }}$, and a periodic grating of gold stripes. The width of the stripes is $w$, the grating periodicity is $p$ (Fig. 1(a)), and the thickness of the gold stripes is $h_{\mathrm{Au}}$. The cavity under one stripe constitutes a Fabry-Perot (FP) resonator, where two plasmon waves propagate: a plasmon wave at the interface film/gap and another plasmon wave at the interface gap/stripe. These plasmon waves are coupled together [16] and the resulting gap mode travels along the stripe width [2]. The gap mode can be excited in normal incidence by a TM-polarized plane wave (Fig. 1(a)). The fundamental MIM mode is characterized by confined electromagnetic fields within the gap, with an enhanced electric field at the cavity corners and a maximum of magnetic field at the center of the cavity. The reflectivity spectra were numerically computed using RMCA technique (Rigorous Maxwell formulation and polynomial Constitutive equations Approximation) $[17,18]$. This approach is defined by a decomposition of the field on a basis of vertically propagating modes (along z-axis) and relies on a scattering matrices algorithm. In this study, we fixed the resonance wavelength $\lambda$ at $3 \mu \mathrm{m}$ and the thickness of the gold stripes at $50 \mathrm{~nm}$. The refractive index of silica was equal 1.42 [19], and the gold permittivity was set 

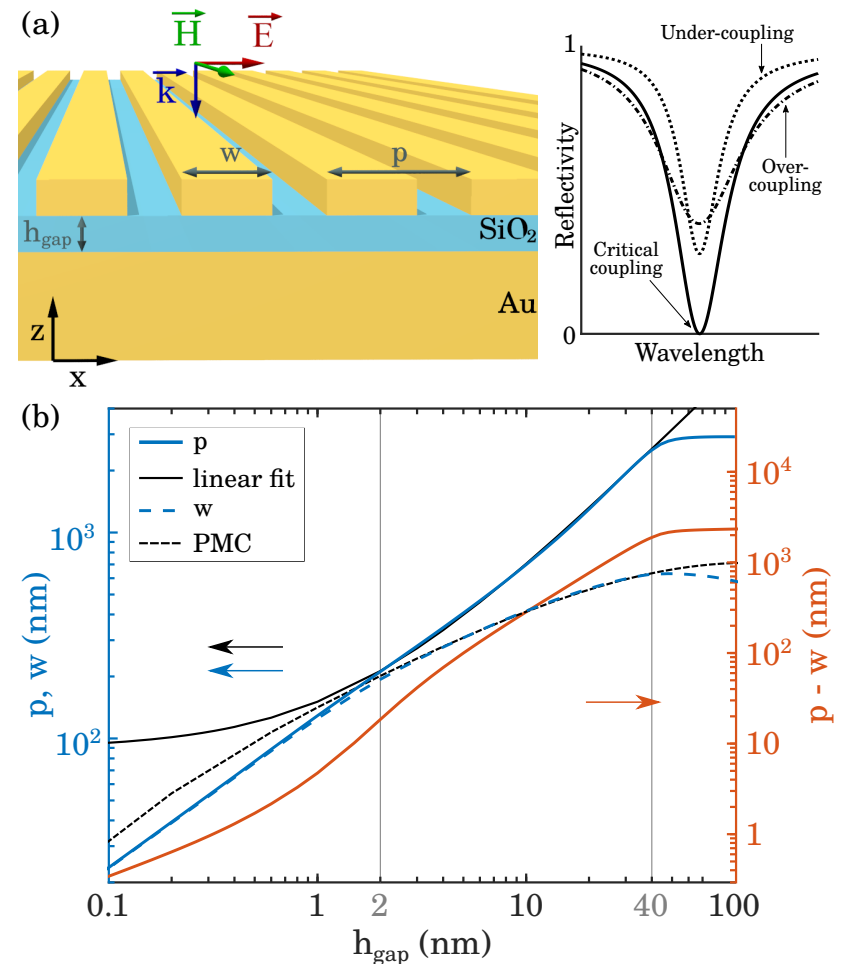

Fig. 1. (a) 3D Schematic view of MIM antennas, consisting of a gold mirror, $\mathrm{a} \mathrm{SiO}_{2}$ layer, and a periodic grating of gold stripes. Typical reflectivity spectra for three cases: under-coupling, critical coupling, and over-coupling. (b) On the left, optimal periodicity $p$ (blue solid line) and width $w$ (blue dashed line) at critical coupling as a function of the gap thickness $h_{\text {gap }}$, superimposed with a linear fit of $p\left(p=61.1 h_{\text {gap }}+91.7\right.$, black solid line) and the width satisfying PMC (black dashed line). On the right, the width of the remaining space between two neighboring antennas $(p-w$ in red).

to $-416.60+47.51 i$, in accordance with recent studies [20, 21] Then, we determined the conditions leading to critical coupling, which corresponds to a total absorption, i.e. a reflectivity close to zero, through calculating the width of the stripes and the periodicity of the grating ( $w$ and $p$ ) for gap thicknesses ranging from 0.1 to $100 \mathrm{~nm}$. We found that critical coupling was achievable for every thickness of gap. The critical coupling position was obtained for a normalized reflected intensity below $10^{-8}$.

The results of these calculations are shown in Fig. 1(b). Three domains are identified. Perfect MIM mode extends from 2 to $40 \mathrm{~nm}$. For these thicknesses, the stripe width perfectly satisfies the phase-matching condition (PMC) [22] in a FP resonator: $w=$ $\frac{\lambda}{2 n_{\text {eff }}^{\text {gap }}}\left[1-\frac{\varphi}{\pi}\right]$, with $n_{\text {eff }}^{\text {gap }}$ the effective index of the mode and $\varphi$ the reflection phase at a single corner of the cavity. The grating periodicity and the gap thickness follow a linear condition.

For gap thicker than $40 \mathrm{~nm}$, the grating periodicity saturates before $3 \mu \mathrm{m}$. It results from the coupling between MIM mode and SPP mode propagating at the metal $/ \mathrm{SiO}_{2}$ interface. If $p$ were greater than $\lambda$, diffraction modes would appear with electromagnetic fields radiating along new directions.

Below $2 \mathrm{~nm}$, the space between two adjacent stripes is in the same order of magnitude of the gap thickness, facilitating the coupling between neighboring antennas and modifying the (a)
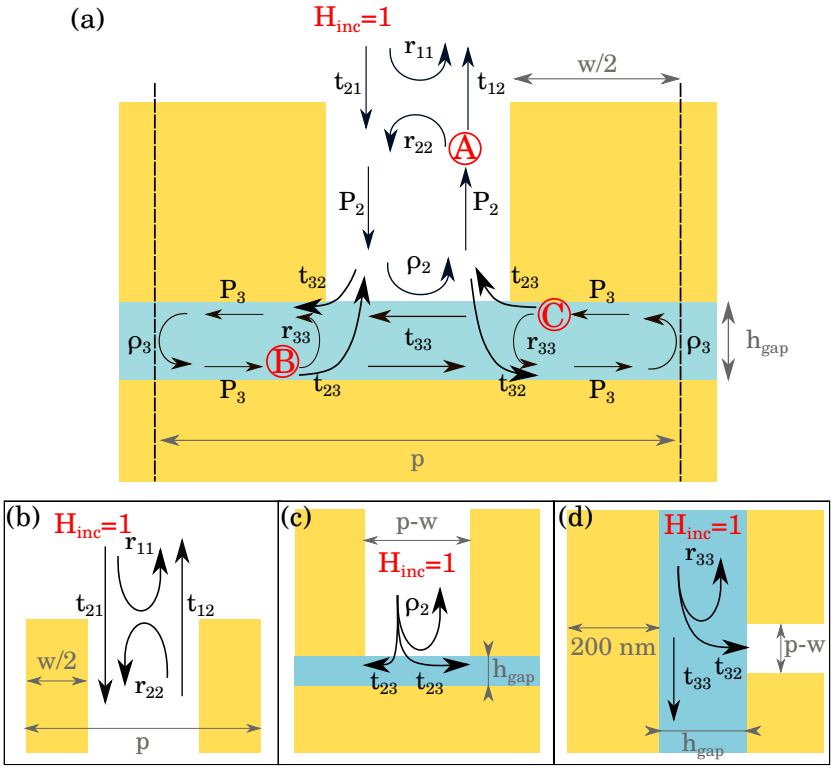

Fig. 2. (a) Schematic cross section of two half-antennas. The parameters of the S-matrices are presented on the figure. The system is excited by a magnetic field amplitude set to unity and polarized along y. The system is decomposed into three configurations to extract the parameters of the S-matrices: (b) top of the vertical air slit, (c) bottom of the vertical air slit, and (d) the two half-cavities. The amplitude of the magnetic field is extracted at three nodes. A: top of the vertical air slit, B: border of one half-cavity, and C: border of the other half-cavity.

properties of the MIM mode.

To investigate the origin of critical coupling in gap antennas with gaps ranging from 0.1 to $100 \mathrm{~nm}$, we develop an analytical model that accounts for the space between two gold stripes in nanogap antennas. It has been previously demonstrated that one horizontal MIM resonator is equivalent to two vertical slits [23]: the slits can be considered separately and the field can be seen as being totally reflected at the middle of the cavity. However, for sub-nanometer gap antennas, the system can no longer be seen as two independent slits because the space between two stripes is reduced for maintaining critical coupling. This space is integrated into our model as a third slit of air, where the effective index becomes highly greater than 1 .

In this analytical model, we determine the exchanges between the three slits (Fig. 2(a)). First, the incident magnetic field, set to unity, can either reflect onto the grating $\left(r_{11}\right)$ or enter into the vertical slit $\left(t_{21}\right)$. After propagation within the slit $\left(P_{2}\right)$, the field can enter under one or the other half-stripe (both $t_{32}$ ), or it can get reflected on top of the silica layer $\left(\rho_{2}\right)$. When the field is transmitted toward the silica layer, it propagates $\left(P_{3}\right)$, reflects $\left(\rho_{3}\right)$, and propagates again $\left(P_{3}\right.$, nodes $\mathrm{B}$ and $\left.\mathrm{C}\right)$ to exit toward the other half-cavity $\left(t_{33}\right)$, the vertical slit $\left(t_{23}\right)$, or reflect again $\left(r_{33}\right)$, and so on. When the field gets reflected on top of the $\mathrm{SiO}_{2}$ layer, it propagates backwards until reaching the interface slit/free space (node A), where it can either exit toward free space $\left(t_{12}\right)$ or gets reflected on the top of the slit $\left(r_{22}\right)$.

This intertwined system can be decomposed into three independent configurations: the top of the vertical air slit (Fig. 2(b)), the interface air/silica with the silica layer at the bottom of the slit (Fig. 2(c)), and the two half-cavities (Fig. 2(d)). Periodic 
boundary condition is here equivalent to a total internal reflection at the end of a half-cavity, leading to $\rho_{3}=1$. The propagators inside the vertical slit and one half-stripe depend on the effective index of their respective medium: $P_{2}=\exp \left(i k_{0} n_{\mathrm{eff}}^{\text {air }} h_{\mathrm{Au}}\right)$ and $P_{3}=\exp \left(i k_{0} n_{\text {eff }}^{\text {gap }} w / 2\right)$, with $k_{0}=2 \pi / \lambda$. All quantities were deduced from RMCA modal method into these three configurations. $r_{11}, r_{22}, t_{12}, t_{21}$ and $n_{\text {eff }}^{\text {air }}$ were deduced from Fig. 2(b) configuration. $\rho_{2}$ and $t_{32}$ were deduced from Fig. 2(c). $t_{33}$, $r_{33}, t_{23}$ and $n_{\text {eff }}^{\text {gap }}$ were deduced from Fig. 2(d). The effective indices are deduced from the fundamental eigenmode inside each slab. Reflectivities and transmissivities are the related Smatrices elements, except the two orthogonal transmissions $t_{23}$ and $t_{32}$ : independent slits were considered for determining the projection of the combination of all the vertical modes onto the horizontal propagating mode.

At steady-state, the total reflectivity can be written as:

$$
r_{\text {tot }}=r_{11}+A t_{12}
$$

with $A$, the amplitude of the magnetic field at node $\mathrm{A}$ in Fig. 2 , satisfying the following equations:

$$
\begin{gathered}
A=P_{2}^{2} \rho_{2} t_{21}+P_{2}^{2} \rho_{2} r_{22} A+P_{2} t_{23} B+P_{2} t_{23} C \\
B=P_{3}^{2} \rho_{3}\left(t_{32} P_{2} t_{21}+t_{32} P_{2} r_{22} A+r_{33} B+t_{33} C\right) \\
C=P_{3}^{2} \rho_{3}\left(t_{32} P_{2} t_{21}+t_{32} P_{2} r_{22} A+t_{33} B+r_{33} C\right)
\end{gathered}
$$

with $B$ and $C$, the amplitude of the magnetic field at nodes $B$ and $C$, respectively. The total response does not depend on the normalization of the eigenvectors in each single layer, however transmissivities $t_{12}$ and $t_{21}$ do. In order to get rid of this effect, we factorize the equations by their product $t_{12} \times t_{21}$. For each gap thickness, a small deviation of $t_{23} \times t_{32}$ has been considered to remove any uncertainty due to the arbitrary origin taken for their phase and permitted to lead to a total reflectivity converging toward the value deduced above. We conducted the calculation until an absolute error of $10^{-10}$ was reached.

As we previously assumed, the studied system presents three domains as a function of the gap thickness, illustrated by the evolution of the Fresnel's coefficient and effective indices (Fig. $3)$. As the gap thickness decreases, the modulus of $t_{12} \times t_{21}$ decreases, indicating the necessity to reduce the incident field (i.e. the period) in order to maintain the critical coupling. ${ }^{1}$ Furthermore, the real part of the effective index of the gap mode $\left(\Re\left(n_{\text {eff }}^{\text {gap }}\right)\right)$ increases due to a stronger coupling between the two surface plasmons. The corresponding imaginary part increases as well, demonstrating a stronger absorption.

For gap thicknesses between 2 to $40 \mathrm{~nm}$, we observe the typical behavior of a FP resonator illustrated by a high reflection on both sides of the cavity $\left(r_{33}\right.$ is real negative and lower than $-0.8)$ and a week coupling between adjacent antennas $\left(\left|t_{33}\right|<\right.$ $0.3)$.

Gaps thicker than $40 \mathrm{~nm}$ still show a noticeable MIM mode as $\Re\left(n_{\text {eff }}^{\text {gap }}\right)$ in the $\mathrm{SiO}_{2}$ gap remains above the bulk refractive index. The emergence of an SPP mode implies fewer exchange between the vertical slit and the gap layer, counterbalanced by a slight increase of $\left|t_{33}\right|$ and decrease of $\left|r_{33}\right|$. In this domain, the vertical slit does not show any vertical resonance $\left(\Re\left(n_{\text {eff }}^{\text {air }}\right)=1\right)$.

For gaps thinner than $2 \mathrm{~nm}$, a resonance appears in the vertical air slit, as confirmed by the rise of the effective index of

\footnotetext{
${ }^{1}$ The turning points observed on $r_{33}$ and $t_{33}$ for $h_{\text {gap }}=33 \mathrm{~nm}$ are due to a FP mode in the air slit between two adjacent antennas $(p-w=1500 \mathrm{~nm})$. This mode is not excited at normal incidence but it introduces a noteworthy high transmissivity between antennas at resonance.
}
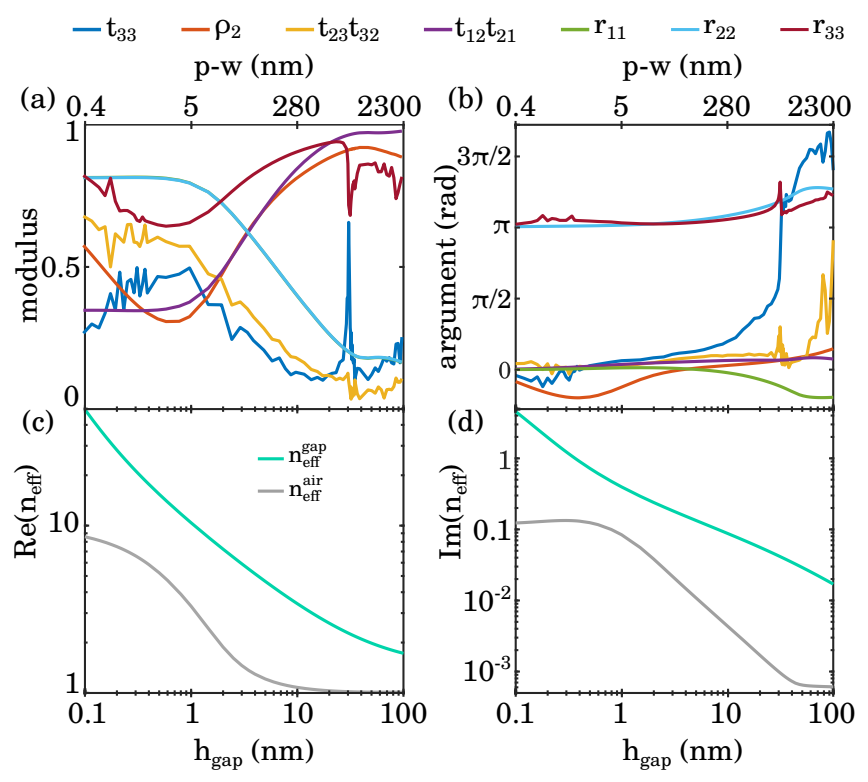

Fig. 3. Modulus (a) and argument (b) of Fresnel coefficients used in our model. All parameters are presented as a function of $h_{\text {gap }}$ in a logarithmic scale. The space $p-w$ between antennas is shown as an indication for $h_{\text {gap }}=0.1,1,10$ and $100 \mathrm{~nm}$. Note that $\left|r_{11}\right| \simeq\left|r_{22}\right|$. Real (c) and imaginary (d) parts of the effective indices in the air slit and $\mathrm{SiO}_{2}$ gap.

the mode in the air slit above 1 . Thus, the system is made of three coupled resonators. As the gap thickness decreases, (i) the coupling between the horizontal slits increases ( $\left|t_{33}\right|$ increases), (ii) the coupling between the vertical slit and the horizontal slits increases $\left(\left|t_{23} \times t_{32}\right|\right.$ increases), (iii) the confinement within the horizontal slits increases ( $\Re\left(n_{\text {eff }}^{\text {gap }}\right)$ increases) accompanied by an increase of the absorption $\left(\Im\left(n_{\text {eff }}^{\text {gap }}\right)\right)$.

Confinement inside the total system benefits from a much stronger coupling between neighboring antennas, assisted by the dual role of the vertical slit: giving access to the half-cavities and storing a little energy by resonating. The lower exchange between free-space and the structure is compensated by a higher storage and stronger exchanges inside the system: the vertical slit gives more flow to both $\mathrm{SiO}_{2}$ half-cavities, which also exchange with one another.

Indeed, the maps of the electric field components (Fig. 4) for a gap of $1 \mathrm{~nm}$, show a strong field inside the gap in agreement with MIM mode properties, but also exhibit a large field in the vertical space between gold stripes. It reveals the coupling between neighboring antennas, characterized by a nearly constant field inside the vertical slit, close to the value of the field within the $\mathrm{SiO}_{2}$ gap.

Besides, below $0.5 \mathrm{~nm}$ the width is lower than twice the penetration depth: at this scale, evanescent modes from each side of a stripe couple together within the metal, leading to an attenuated confinement and a higher absorption inside one single nanoresonator [22]. Antennas have to be brought closer to counterbalance this effect. A side effect of this coupling is a lowering of the effective index inside the slit compared with independent slits (i.e. larger stripes), resulting in a saturation of the top reflectivity $r_{11}$ around -0.8 .

It is worth noticing that for the thinnest gaps (i.e. near 0.1 $\mathrm{nm})$, gap modes may no longer exist: the imaginary part of 


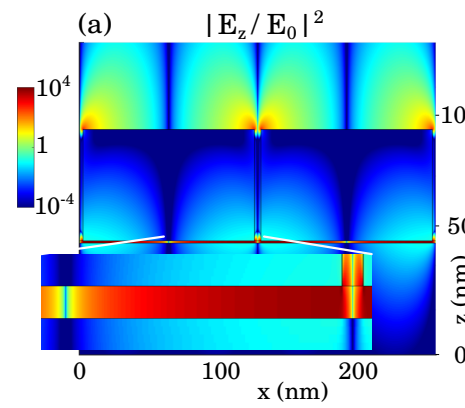

(b)

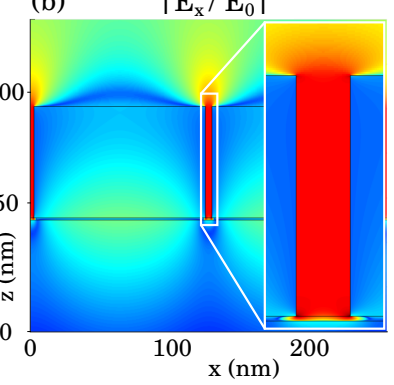

Fig. 4. Maps of the intensity of the electric field in logarithmic scale, normalized by the illuminating field $E_{0}$ for a gap of $1 \mathrm{~nm}$ : (a) z-component and (b) $\mathrm{x}$-component. This structure is at critical coupling with $p=129 \mathrm{~nm}$ and $w=124.3 \mathrm{~nm}$.

the index of the effective mode becomes close to its real part. Furthermore, the study performed in this paper is fully classical, and non-local and tunneling effects are not included [24, 25] Although quantum plasmonics effects have not been accounted for, this study shows interesting aspects for designing MIM nanostructures at critical coupling and understanding the role of each element in the global response. This model can be applied to higher wavelengths, thus extending its validity.

For small gap thicknesses $(<2 \mathrm{~nm})$, the structured gold layer needs to be very dense to maintain critical coupling $(p-w<20 \mathrm{~nm}$ and $w<190 \mathrm{~nm}$, leading to a filling factor greater than $90 \%$ ). This design is hard to fabricate and the optical response can be very sensitive to fluctuations in the antennas dimensions. This fabrication challenge can be overcome through diverse techniques, such as Atomic Layer Deposition [26, 27], Focused Ion Beam milling [28], or assembly of cubic nanoparticles [29]. Two-dimensional array can also be considered, introducing modes along both $\mathrm{x}$ - and $\mathrm{y}$-axes. Despite the more complex situation due to mode coupling, the changes in results should be minimal under polarized light.

Critical coupling can also be reached through changing other parameters, such as varying the thickness of the gold stripes or etching the insulator layer at the bottom of the vertical slit [30]. Furthermore, it can be convenient to introduce an adhesion layer between gold and silica to improve the adhesion of silica on gold.

To conclude, critically coupled MIM nanoresonators can be obtained for any thickness of insulating gap. Three ranges have been identified: the regular MIM mode, its coupling with SPP for thickness higher than $40 \mathrm{~nm}$ and gap plasmon mode for thickness below $2 \mathrm{~nm}$. This relation between the width, the periodicity and the thickness of the gap gives simple rules to design a perfect absorber at a fixed wavelength. An analytical description of the system discussed the coupling between two adjacent half-MIM and revealed the central role of the vertical slit for thinner gaps. This system can be described by a unique system of equations, valid for any thickness from 0.1 to $100 \mathrm{~nm}$.

\section{FUNDING INFORMATION}

This work was partially supported by the Agence Nationale de la Recherche under the project HORUS ANR-16-CE39-0007-03.

\section{REFERENCES}

1. P. Muehlschlegel, H.-J. Eisler, O. J. Martin, B. Hecht, and D. Pohl, science 308, 1607 (2005).

2. G. Lévêque and O. J. Martin, Opt. letters 31, 2750 (2006).

3. A. Kinkhabwala, Z. Yu, S. Fan, Y. Avlasevich, K. Müllen, and W. Moerner, Nat. Photonics 3, 654 (2009).

4. C. Deeb, Z. Guo, A. Yang, L. Huang, and T. W. Odom, Nano letters 18, 1454 (2018).

5. D. R. Ward, F. Hüser, F. Pauly, J. C. Cuevas, and D. Natelson, Nat. nanotechnology 5, 732 (2010).

6. A. Cattoni, P. Ghenuche, A.-M. Haghiri-Gosnet, D. Decanini, J. Chen, J.-L. Pelouard, and S. Collin, Nano letters 11, 3557 (2011).

7. Z. Dong, M. Asbahi, J. Lin, D. Zhu, Y. M. Wang, K. Hippalgaonkar, H.-S. Chu, W. P. Goh, F. Wang, Z. Huang et al., Nano letters 15, 5976 (2015).

8. J. B. Lassiter, X. Chen, X. Liu, C. Ciracì, T. B. Hoang, S. Larouche, S.-H. Oh, M. H. Mikkelsen, and D. R. Smith, Acs Photonics 1, 1212 (2014).

9. X. Chen, C. Ciracì, D. R. Smith, and S.-H. Oh, Nano letters 15, 107 (2014).

10. G. M. Akselrod, C. Argyropoulos, T. B. Hoang, C. Ciracì, C. Fang, J. Huang, D. R. Smith, and M. H. Mikkelsen, Nat. Photonics 8, 835 (2014).

11. J. Kern, R. Kullock, J. Prangsma, M. Emmerling, M. Kamp, and B. Hecht, Nat. Photonics 9, 582 (2015).

12. M. Buret, A. V. Uskov, J. Dellinger, N. Cazier, M.-M. Mennemanteuil, J. Berthelot, I. V. Smetanin, I. E. Protsenko, G. Colas-des Francs, and A. Bouhelier, Nano letters 15, 5811 (2015).

13. S. P. Gurunarayanan, N. Verellen, V. S. Zharinov, F. James Shirley, V. V. Moshchalkov, M. Heyns, J. Van de Vondel, I. P. Radu, and P. Van Dorpe, Nano letters 17, 7433 (2017).

14. S. Collin, Reports on Prog. Phys. 77, 126402 (2014).

15. J. R. Piper and S. Fan, ACS Photonics 1, 347 (2014).

16. S. Collin, F. Pardo, and J.-L. Pelouard, Opt. Express 15, 4310 (2007).

17. S. Vassant, F. Pardo, P. Bouchon, R. Haïdar, F. Marquier, J. J. Greffet, and J. L. Pelouard, Appl. Phys. Lett. 100, 091103 (2012).

18. B. Portier, F. Pardo, P. Bouchon, R. Haïdar, and J.-L. Pelouard, JOSA A 30, 573 (2013).

19. J. Kischkat, S. Peters, B. Gruska, M. Semtsiv, M. Chashnikova, M. Klinkmüller, O. Fedosenko, S. Machulik, A. Aleksandrova, G. Monastyrskyi et al., Appl. optics 51, 6789 (2012).

20. C. Koechlin, P. Bouchon, F. Pardo, J. Jaeck, X. Lafosse, J.-L. Pelouard, and R. Haïdar, Appl. Phys. Lett. 99, 241104 (2011).

21. R. L. Olmon, B. Slovick, T. W. Johnson, D. Shelton, S.-H. Oh, G. D. Boreman, and M. B. Raschke, Phys. Rev. B 86, 235147 (2012).

22. J. Yang, C. Sauvan, A. Jouanin, S. Collin, J.-L. Pelouard, and P. Lalanne, Opt. Express 20, 16880 (2012).

23. C. Koechlin, P. Bouchon, F. Pardo, J.-L. Pelouard, and R. Haïdar, Opt. Express 21, 7025 (2013).

24. A. Moreau, C. Ciracì, and D. R. Smith, Phys. Rev. B 87, 045401 (2013).

25. W. Zhu, R. Esteban, A. G. Borisov, J. J. Baumberg, P. Nordlander, H. J. Lezec, J. Aizpurua, and K. B. Crozier, Nat. communications 7, 11495 (2016).

26. R. Alaee, C. Menzel, U. Huebner, E. Pshenay-Severin, S. Bin Hasan, T. Pertsch, C. Rockstuhl, and F. Lederer, Nano letters 13, 3482 (2013).

27. X. Chen, H.-R. Park, M. Pelton, X. Piao, N. C. Lindquist, H. Im, Y. J. Kim, J. S. Ahn, K. J. Ahn, N. Park et al., Nat. communications 4, 2361 (2013).

28. K. Chen, G. Razinskas, H. Vieker, H. Gross, X. Wu, A. Beyer, A. Gölzhäuser, and B. Hecht, Nanoscale 10, 17148 (2018).

29. J. B. Lassiter, F. McGuire, J. J. Mock, C. Ciracì, R. T. Hill, B. J. Wiley, A. Chilkoti, and D. R. Smith, Nano Lett. 13, 5866 (2013). PMID: 24199752.

30. J.-M. Manceau, S. Zanotto, I. Sagnes, G. Beaudoin, and R. Colombelli, Appl. Phys. Lett. 103, 091110 (2013). 


\section{FULL REFERENCES}

1. P. Muehlschlegel, H.-J. Eisler, O. J. Martin, B. Hecht, and D. Pohl, "Resonant optical antennas," science. 308, 1607-1609 (2005).

2. G. Lévêque and O. J. Martin, "Tunable composite nanoparticle for plasmonics," Opt. letters 31, 2750-2752 (2006).

3. A. Kinkhabwala, Z. Yu, S. Fan, Y. Avlasevich, K. Müllen, and W. Moerner, "Large single-molecule fluorescence enhancements produced by a bowtie nanoantenna," Nat. Photonics 3, 654 (2009).

4. C. Deeb, Z. Guo, A. Yang, L. Huang, and T. W. Odom, "Correlating nanoscopic energy transfer and far-field emission to unravel lasing dynamics in plasmonic nanocavity arrays," Nano letters 18, 1454-1459 (2018).

5. D. R. Ward, F. Hüser, F. Pauly, J. C. Cuevas, and D. Natelson, "Optical rectification and field enhancement in a plasmonic nanogap," Nat. nanotechnology 5, 732 (2010).

6. A. Cattoni, P. Ghenuche, A.-M. Haghiri-Gosnet, D. Decanini, J. Chen, J.-L. Pelouard, and S. Collin, " $\lambda 3 / 1000$ plasmonic nanocavities for biosensing fabricated by soft uv nanoimprint lithography," Nano letters 11, 3557-3563 (2011).

7. Z. Dong, M. Asbahi, J. Lin, D. Zhu, Y. M. Wang, K. Hippalgaonkar, H.-S Chu, W. P. Goh, F. Wang, Z. Huang et al., "Second-harmonic generation from sub- $5 \mathrm{~nm}$ gaps by directed self-assembly of nanoparticles onto template-stripped gold substrates," Nano letters 15, 5976-5981 (2015).

8. J. B. Lassiter, X. Chen, X. Liu, C. Ciracì, T. B. Hoang, S. Larouche, S.-H. Oh, M. H. Mikkelsen, and D. R. Smith, "Third-harmonic generation enhancement by film-coupled plasmonic stripe resonators," Acs Photonics 1, 1212-1217 (2014).

9. X. Chen, C. Ciracì, D. R. Smith, and S.-H. Oh, "Nanogap-enhanced infrared spectroscopy with template-stripped wafer-scale arrays of buried plasmonic cavities," Nano letters 15, 107-113 (2014).

10. G. M. Akselrod, C. Argyropoulos, T. B. Hoang, C. Ciracì, C. Fang, J. Huang, D. R. Smith, and M. H. Mikkelsen, "Probing the mechanisms of large purcell enhancement in plasmonic nanoantennas," Nat. Photonics 8, 835 (2014).

11. J. Kern, R. Kullock, J. Prangsma, M. Emmerling, M. Kamp, and B. Hecht, "Electrically driven optical antennas," Nat. Photonics 9, 582 (2015).

12. M. Buret, A. V. Uskov, J. Dellinger, N. Cazier, M.-M. Mennemanteuil, J. Berthelot, I. V. Smetanin, I. E. Protsenko, G. Colas-des Francs, and A. Bouhelier, "Spontaneous hot-electron light emission from electronfed optical antennas," Nano letters 15, 5811-5818 (2015).

13. S. P. Gurunarayanan, N. Verellen, V. S. Zharinov, F. James Shirley, V. V. Moshchalkov, M. Heyns, J. Van de Vondel, I. P. Radu, and P. Van Dorpe, "Electrically driven unidirectional optical nanoantennas," Nano letters 17, 7433-7439 (2017).

14. S. Collin, "Nanostructure arrays in free-space: optical properties and applications," Reports on Prog. Phys. 77, 126402 (2014).

15. J. R. Piper and S. Fan, "Total absorption in a graphene monolayer in the optical regime by critical coupling with a photonic crystal guided resonance," ACS Photonics 1, 347-353 (2014).

16. S. Collin, F. Pardo, and J.-L. Pelouard, "Waveguiding in nanoscale metallic apertures," Opt. Express 15, 4310-4320 (2007).

17. S. Vassant, F. Pardo, P. Bouchon, R. Haïdar, F. Marquier, J. J. Greffet, and J. L. Pelouard, "Influence of a depletion layer on localized surface waves in doped semiconductor nanostructures," Appl. Phys. Lett. 100, 091103 (2012).

18. B. Portier, F. Pardo, P. Bouchon, R. Haïdar, and J.-L. Pelouard, "Fast modal method for crossed grating computation, combining finite formulation of maxwell equations with polynomial approximated constitutive relations," JOSA A 30, 573-581 (2013).

19. J. Kischkat, S. Peters, B. Gruska, M. Semtsiv, M. Chashnikova, M. Klinkmüller, O. Fedosenko, S. Machulik, A. Aleksandrova, G. Monastyrskyi et al., "Mid-infrared optical properties of thin films of aluminum oxide, titanium dioxide, silicon dioxide, aluminum nitride, and silicon nitride," Appl. optics 51, 6789-6798 (2012).

20. C. Koechlin, P. Bouchon, F. Pardo, J. Jaeck, X. Lafosse, J.-L. Pelouard, and R. Haïdar, "Total routing and absorption of photons in dual color plasmonic antennas," Appl. Phys. Lett. 99, 241104 (2011).
21. R. L. Olmon, B. Slovick, T. W. Johnson, D. Shelton, S.-H. Oh, G. D. Boreman, and M. B. Raschke, "Optical dielectric function of gold," Phys. Rev. B 86, 235147 (2012).

22. J. Yang, C. Sauvan, A. Jouanin, S. Collin, J.-L. Pelouard, and P. Lalanne, "Ultrasmall metal-insulator-metal nanoresonators: impact of slow-wave effects on the quality factor," Opt. Express 20, 16880-16891 (2012).

23. C. Koechlin, P. Bouchon, F. Pardo, J.-L. Pelouard, and R. Haïdar, "Analytical description of subwavelength plasmonic mim resonators and of their combination," Opt. Express 21, 7025-7032 (2013).

24. A. Moreau, C. Ciracì, and D. R. Smith, "Impact of nonlocal response on metallodielectric multilayers and optical patch antennas," Phys. Rev. B 87, 045401 (2013).

25. W. Zhu, R. Esteban, A. G. Borisov, J. J. Baumberg, P. Nordlander, H. J. Lezec, J. Aizpurua, and K. B. Crozier, "Quantum mechanical effects in plasmonic structures with subnanometre gaps," Nat. communications 7, 11495 (2016).

26. R. Alaee, C. Menzel, U. Huebner, E. Pshenay-Severin, S. Bin Hasan, T. Pertsch, C. Rockstuhl, and F. Lederer, "Deep-subwavelength plasmonic nanoresonators exploiting extreme coupling," Nano letters 13, 3482-3486 (2013).

27. X. Chen, H.-R. Park, M. Pelton, X. Piao, N. C. Lindquist, H. Im, Y. J. Kim, J. S. Ahn, K. J. Ahn, N. Park et al., "Atomic layer lithography of waferscale nanogap arrays for extreme confinement of electromagnetic waves," Nat. communications 4, 2361 (2013).

28. K. Chen, G. Razinskas, H. Vieker, H. Gross, X. Wu, A. Beyer, A. Gölzhäuser, and B. Hecht, "High-Q, low-mode-volume and multiresonant plasmonic nanoslit cavities fabricated by helium ion milling," Nanoscale 10, 17148-17155 (2018).

29. J. B. Lassiter, F. McGuire, J. J. Mock, C. Ciracì, R. T. Hill, B. J. Wiley, A. Chilkoti, and D. R. Smith, "Plasmonic waveguide modes of filmcoupled metallic nanocubes," Nano Lett. 13, 5866-5872 (2013). PMID: 24199752

30. J.-M. Manceau, S. Zanotto, I. Sagnes, G. Beaudoin, and R. Colombelli, "Optical critical coupling into highly confining metal-insulator-metal resonators," Appl. Phys. Lett. 103, 091110 (2013). 